\title{
Enhancement of Fluorescence and Photo Stability Based on Interaction of Fluorescent Dyes with Silver Nanoparticles for Luminescent Solar Concentrators
}

\author{
A. F. Mansour*, M. Gabr, S. H. El-Molla \\ Physics department, Faculty of Science, Zagazig University, \\ Zagazig, Egypt.
}

\begin{abstract}
Silver nanoparticles (NPS) in Triton X-100 were characterized by X-ray diffraction (XRD) and UV-Vis absorption spectra. UV-Vis spectrum showed a single peak at $442 \mathrm{~nm}$ due to the surface Plasmon resonance (SPR). Position of $S P R$ peak exhibited a red shift after the sample was exposed to UV irradiation (unfiltered light). The optical band gap values have a reduction from 2.46 to $2.37 \mathrm{eV}$ after irradiation for 960 minutes. Such reduction in optical band gap may be due to change in particle size which calculated using Mie theory. For Luminescent solar concentrators (LSC), it is important to enhance the fluorescence quantum yield (FQY) and photo stability. Our measurements have demonstrated that the addition of Silver nanoparticles to dye solution causes broadening of absorption bands, so the spectral range of sunlight absorbed by LSC has increased. The photo stability of organic dyes used was improved after adding Silver nanoparticles. The area under fluorescence spectra of dyes with Silver NPs increased by 41-31 \% when compared with identical dye concentrations without Silver nanoparticles as a result of interaction of the species with Silver NPs.
\end{abstract}

\section{Introduction}

Luminesent solar concentrators (LSCs) were introduced for the first time in 1976 by Weber and Lambe [1,2] to concentrate both diffuse and direct sunlight and convert it into electricity making expensive tracking unnecessary. The LSCs generally contain fluorescent particles such as organic dyes or quantum dots embedded in a transparent matrix medium such as poly methyl methacylate, poly carbonate, glass, or even a liquid solution. A typical fluorescent collector absorbs the incident sunlight through the front face of a luminescent plate and the re-emitted photons are trapped by total internal reflection (TIR) and directed towards a PV cell generally mounted on the edges of the collector. Despite the Luminescent solar concentrators using liquid solutions contained between transparent plates have received a little attention 
[3, 4] \& do not have any direct practical applications, they represent an interesting fundamental system which can be used for a wide range of theoretical and spectroscopic studies, helping to understand the basic performance of fluorescent dye under illumination, leading to an improved device. Liquid collectors are included in the study for their homogenous nature and the ease with which spectroscopic studies can be under taken in liquid solution.

One of the major factors that affect the efficiency of a LSC module is the fluorescence quantum yield (FQY) of the luminescent species used in its design. Recently, it is well established that the fluorescence of dye molecules can be intensified by their interaction with Silver Plasmon [5-9]. The enhancement of the fluorescence emission of molecules near a metal surface arises from interactions with surface Plasmon resonance (SPR) in the metal particles; these interactions may also result in shorting of the excited-state life time leading to an improvement in the photo stability of the dye [10].

When Silver nanoparticles (NPs) are added to the dye solution, the dye molecules will be adsorbed on islands films of the metallic NPs. Also; when the surface Plasmon resonance (SPR) of the metallic NPs coincides with the dye absorption band, it will modify the intensity of the electromagnetic field around the molecules which will increase the emitted fluorescence intensity [11]. The modification of the electromagnetic field is due to the very high field gradient near the metallic surface [12].

In the present work, we aimed to characterize behavior of Silver NPs before and after UV irradiation and enhance the fluorescence of some organic dyes which used in LSC by adding Silver nanoparticles to the dye solutions. The photo stability and energy gaps of organic dyes before and after adding Silver NPs and after UV irradiation has been investigated.

\section{Experimental Procedures}

The organic dyes used in this research were obtained from Radient Dye Laser Accessories GmBH, Silver NPs was obtained from Merk. Also, the solvent used was supplied by Merk. The samples were irradiated by a 300 watt Xenon arc lamp for 960 minutes with absorbing UV filter and without filter. Absorption spectra were measured from 190-900 nm using UV/Visible absorption spectrometer Perkin-Elmer Lambda 4B. Fluorescence spectra were detected by a Shimadzu RF-5301 PC spectrofluorimeter (Kyoto, Japan) equipped with a $150 \mathrm{~W}$ Xenon lamp and using $1.0 \mathrm{~cm}$ quartz cells.

X-ray diffractometer (XRD) with monochromatic Philips $\mathrm{CuK}_{\alpha}$ $(\lambda=1.54178 \AA)$ radiation source at $40 \mathrm{kV}$ and $20 \mathrm{~mA}$ was used to identify 
phases present in Silver nanoparticles with diffraction angle (20) from $25^{\circ}$ to $85^{\circ}$ and a constant scanning speed of $1 \%$ min. Phase identification was done by matching the characteristic XRD peaks against JCPDS (Joint Committee of Powder Diffraction Standards) cards.

\section{Results and Discussion}

\subsection{Characterization of Silver nanoparticles}

\subsubsection{X-ray diffractometry analysis}

The XRD analysis of the as-cast Silver NPs was performed to elucidate the initial phases, as illustrated in Fig. (1). The broad diffraction peaks of face-centered cubic (fcc) of Silver NPs phase are appeared in the XRD profiles. The results showed that the crystalline size of Silver NPs lies in the range

$11.4 \mathrm{~nm}$.

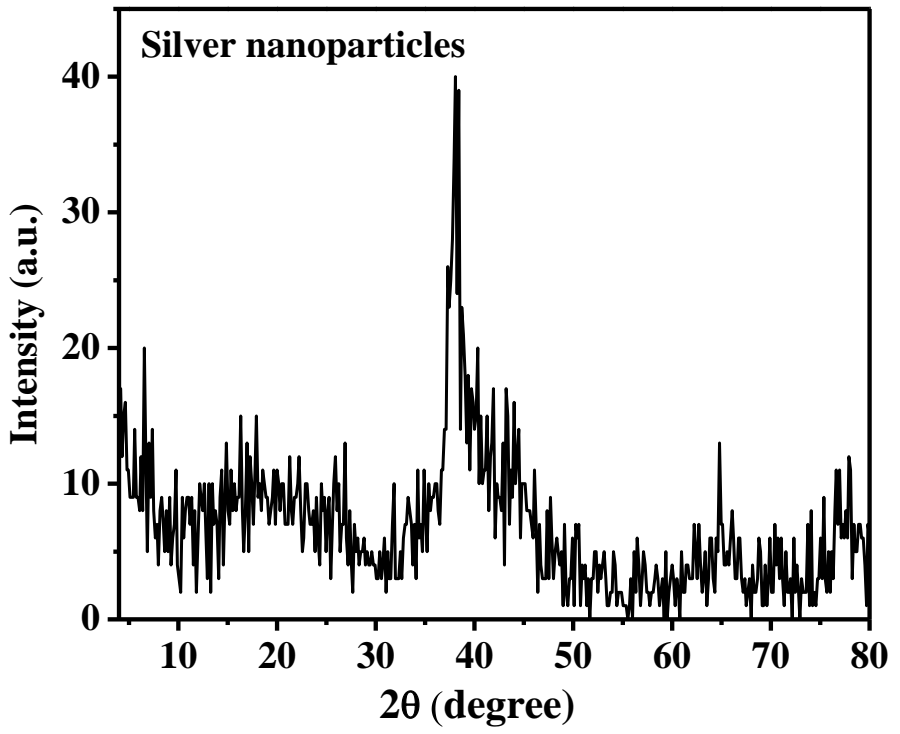

Fig. (1): XRD patterns of the as-cast silver nanoparticles.

\subsubsection{Absorption Spectroscopy}

Figure 2 (curves a to d) represents the optical absorption spectra of Silver nanoparticles in Triton X-100 exposed to UV radiations (unfiltered light) for different times varying from 0 - 960 minutes. Curve (a) in this figure shows surface Plasmon resonance (SPR) peak at $442 \mathrm{~nm}$ with a band width of $83 \mathrm{~nm}$. This intense absorption band is observed due to the collective excitation of all 
the free electrons in the surface of the metal nanoparticles. The particle size of Silver NPs are calculated from half width at half maximum (HWHF) of the optical absorption peaks using Mie theory equation 1 [13-15] and tabulated in Table (1).

$$
2 R=\frac{\lambda_{\max }^{2} V_{f}}{\pi C w}
$$

Where $\lambda_{\max }$ is the wavelength at maximum intensity of the SPR, $V_{f}$ is the velocity of the electron at Fermi levels $\left(1.4 \times 10^{6} \mathrm{~ms}^{-1}\right.$ for Silver), $\mathrm{C}$ is the velocity of light in free space and $\mathrm{w}$ is the half width at half maximum (HWHM).

The absorption band red shifted continuously and HWHM increase from 83 to $132 \mathrm{~nm}$ with increase in exposure time to UV radiations. This red shift and broadening of the peak may be due to the reduction in the particle size of Silver NPs as calculated in Table (1).

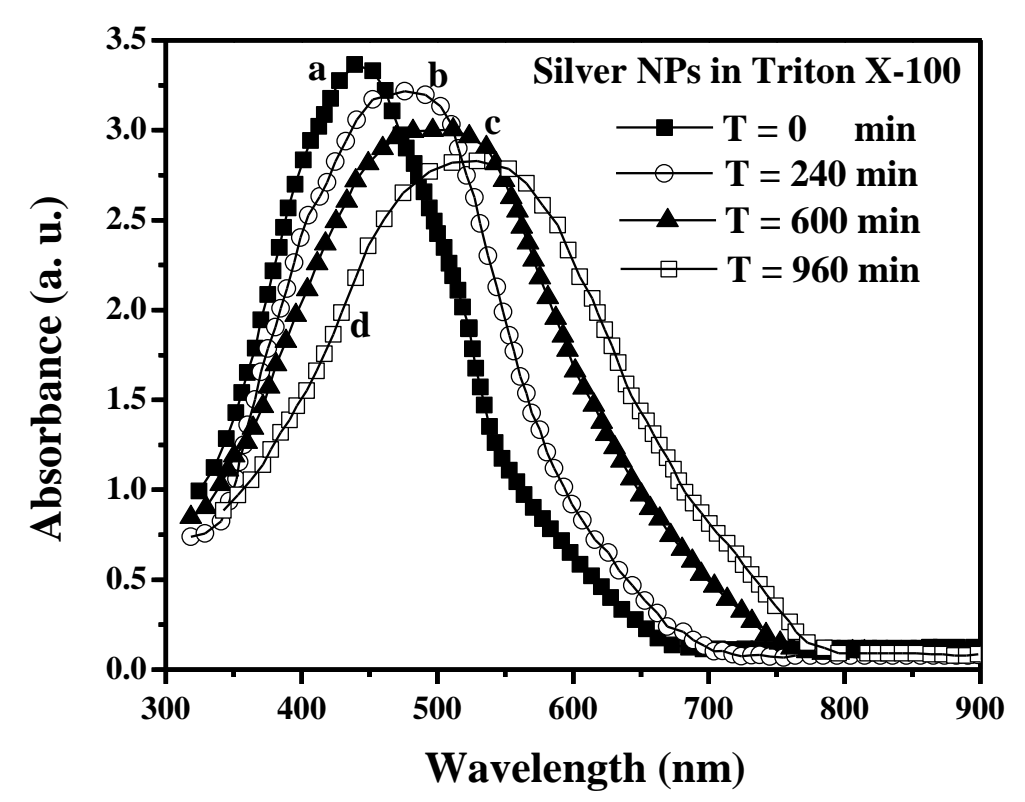

Fig. (2): Absorption Spectra of Silver NPs in Triton X-100 before and after exposed to UV radiations (unfiltered light). 
Table (1): Particle size Calculated from Mie theory.

\begin{tabular}{cccc}
\hline $\begin{array}{c}\text { UV Exposure time } \\
(\mathbf{m i n})\end{array}$ & $\begin{array}{c}\text { SPR Peak } \\
(\mathbf{n m})\end{array}$ & FWHM $(\mathbf{n m})$ & $\begin{array}{c}\text { Particle size } \\
(\mathbf{n m})\end{array}$ \\
\hline 0 & 442 & 83 & 3.50 \\
240 & 469 & 96 & 3.40 \\
600 & 503 & 119 & 3.15 \\
960 & 523 & 132 & 3.07 \\
\hline
\end{tabular}

\subsubsection{Optical band gap}

The optical band gaps $\mathrm{E}_{\mathrm{g}}$ were calculated by the following Tauc's expression [16].

$$
(\alpha h v)^{2}=B\left(h v-E_{g}\right)
$$

where $\alpha$ is the absorption coefficient corresponding to the fundamental absorption edge, $h v$ is the photon energy and $\mathrm{B}$ is the constant of proportionality. The values of optical band gap $E_{g}$ can be deduced from the intercept of the linear fitted lines in the plots of $(\boldsymbol{\alpha h} \mathbf{v})^{2}$ versus $\mathbf{h v}$, as shown in Fig. (3a).
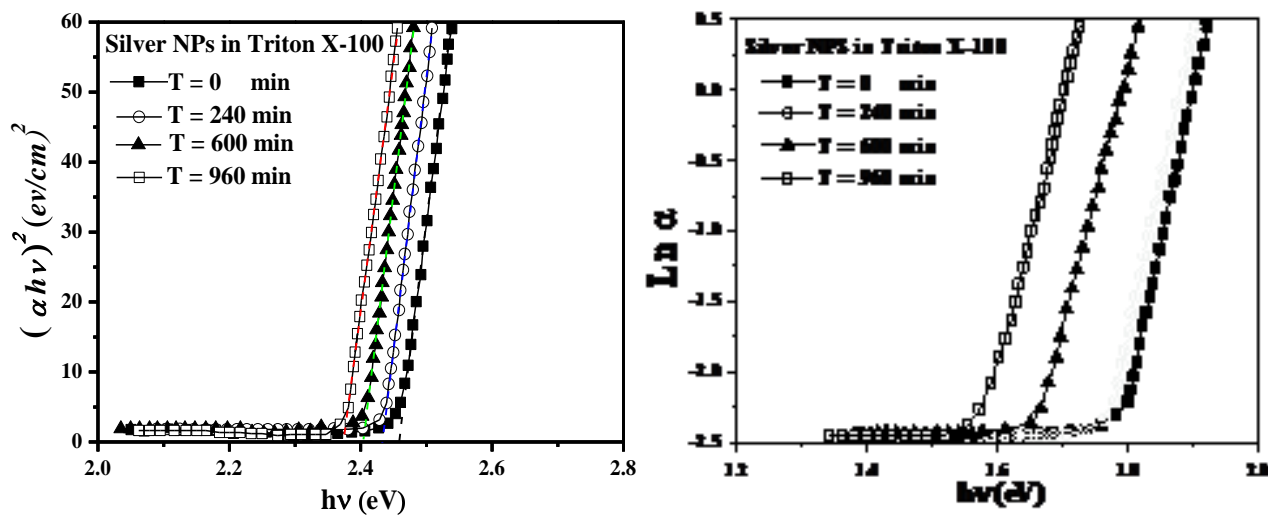

Fig. (3): Plots of $(\alpha h v)^{2}$ and $(\ln \alpha)$ versus hv for Silver NPs before and after exposure to UV irradiations.

The values of optical band gap so determined are listed in Table (2). It is clear from the table that the value of $\mathrm{E}_{\mathrm{g}}$ decreases from 2.46 to $2.37 \mathrm{eV}$ after UV irradiation for 960 minutes which is in accordance with reference [17]. Such reduction in optical band gap may be due to change in particle size which calculated using Mie theory. 
Table (2): The values of optical band gap and Urbach's energy for Silver NPs in Triton X-100 before and after exposure to UV radiation for different times.

\begin{tabular}{ccc}
\hline $\begin{array}{c}\text { UV Exposure time } \\
(\mathbf{m i n})\end{array}$ & $\begin{array}{c}\text { Optical band gap } \mathbf{E}_{\mathbf{g}} \\
(\mathbf{e V})\end{array}$ & $\begin{array}{c}\text { Urbach's energy } \\
\mathbf{E}_{\mathbf{u}}(\mathbf{e V})\end{array}$ \\
\hline 0 & 2.46 & 0.045 \\
240 & 2.43 & 0.047 \\
600 & 2.40 & 0.054 \\
960 & 2.37 & 0.061 \\
\hline
\end{tabular}

The Urbach's energy corresponds to the width of the tail of the localized states within the optical band gap. It is linked to the absorption coefficient in the lower energy region of fundamental edge and can be described by the relation [18]:

$$
\alpha(v)=\alpha_{0} \exp \left[h v / E_{u}\right]
$$

where $\alpha_{o}$ is constant and $E_{u}$ is the Urbach's energy. From equation (3), it is obvious that the plot of $\ln (\alpha)$ versus $h v$ should follow the linear behavior. Fig. $3 b$ presents such plots for Silver NPs before and after UV radiations for different times. The determined values of Urbach's energy are listed in Table 2. It is evident from this table that $E_{u}$ increases from 0.045 to $0.061 \mathrm{eV}$ after irradiation for 960 minutes.

\subsection{Characterization of fluorescent dyes in Triton X-100 with presence of Silver NPs}

\subsubsection{Absorption Spectroscopy}

Figure 4 (curve a, b) shows the absorption spectra of Coumarin 6, Fluoresien and Rhodamine 6G in Triton X-100 without and with Silver NPs. The addition of Silver NPs to dye solution causes the broadening of absorption bands, as shown in Fig. 4 b, so the fluorescent species used utilizes abroad section of solar spectrum. In the absorption spectrum of the dyes, we do not observe an additional peak due to Silver Plasmon which means that we do not have Foster energy transfer but rather a different type of interaction.

Figure (4 c) shows the absorption spectra of dyes with Silver NPs exposed to UV irradiation for 960 minutes. It is clear from this figure that the absorption peak red shifted after UV irradiation. 


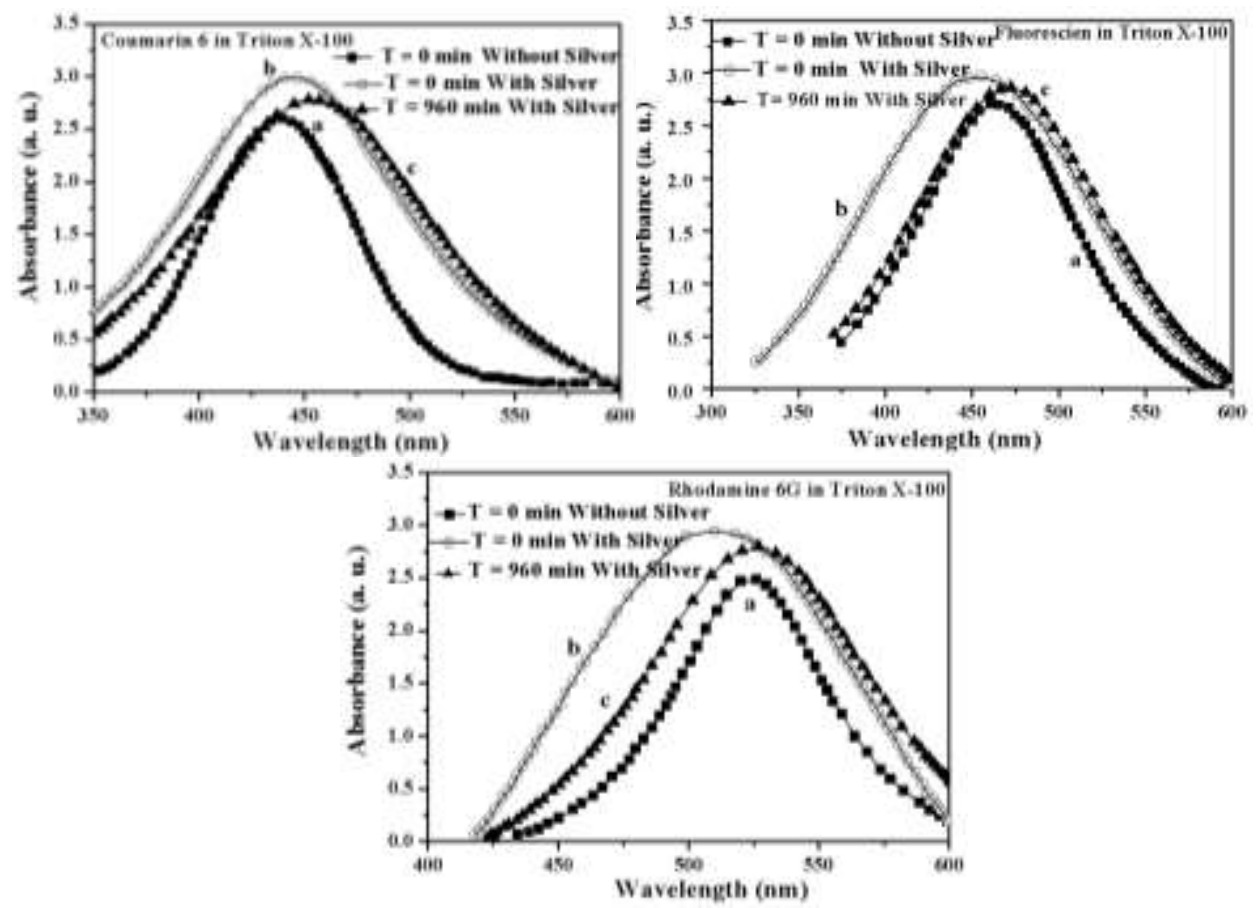

Fig. (4): Absorption spectra of Coumarin 6, Fluorescien and Rhodamine 6G in Triton X-100(a) without Silver, (b) with Silver and (c) with Silver after UV irradiation.

\subsubsection{Optical energy gap}

Figure 5 shows the plots of $(\boldsymbol{\alpha h} \mathbf{v})^{2}$ versus $\mathbf{h} v$ for Coumarin 6, Fluoresien and Rhodamine 6G in Triton X-100 without and with Silver NPs and also after UV irradiation for 960 minutes. Figure 6 shows the plots of $\ln \boldsymbol{\alpha}$ versus hv for Coumarin 6, Fluoresien and Rhodamine 6G in Triton X-100 without and with Silver NPs and also after UV irradiation for 960 minutes. 

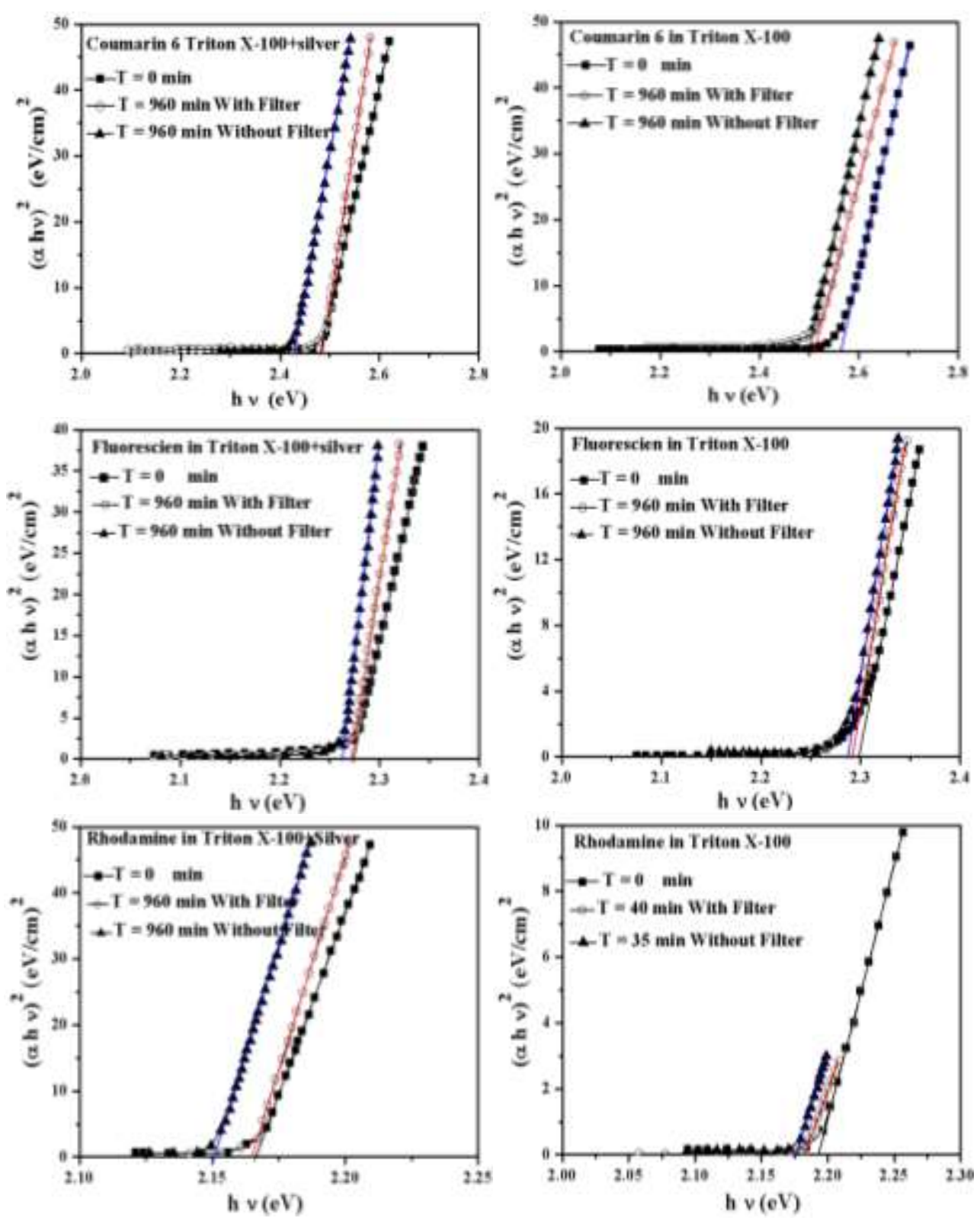

Fig. (5): Plots of $(\alpha h v)^{2}$ versus hv for Coumarin6, Fluorescien and Rhodamine 6G in Triton X-100 without and with Silver NPs before and after exposure to UV irradiations with filter and without filter. 

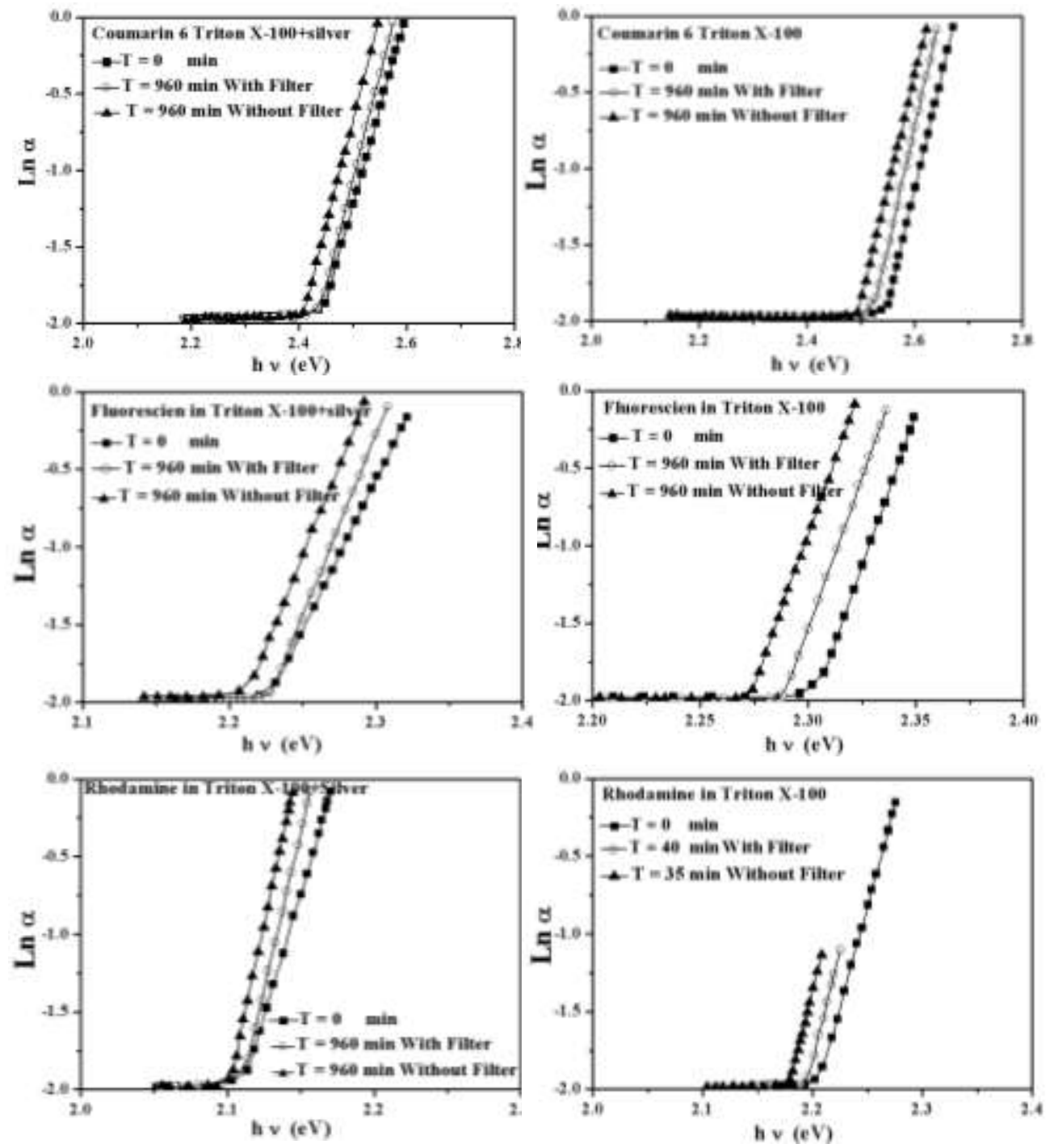

Fig. (6): Plots of $\ln \alpha$ versus $h v$ for Coumarin6, Fluorescien and Rhodamine 6G in Triton X-100 without and with Silver NPs before and after exposure to UV irradiations with filter and without filter.

The values of optical band gap Urbach's energy are listed in Table (3). It is clear from the table that the value of $E_{g}$ decreases and that of $E_{u}$ inceases after adding Silver NPs to dye solution and also after UV irradiation for 960 minutes. Such a reduction in $\mathrm{E}_{\mathrm{g}}$ values can be attributed to be due to the interaction between the electric dipoles of the dye molecules and the surface Plasmon of Silver NPs. Also, there is a clear blue shift in the values of optical 
band gap after UV irradiation (Without filter) for 960 minutes to dye/Silver/ Triton $\mathrm{X}-100$. The change in $\mathrm{E}_{\mathrm{g}}$ with $\mathrm{UV}$ irradiation may be attributed to quantum confinement [19].

Table (3): The values of optical band gap and Urbach's energy for Coumarin 6, Fluorescien and Rhodamine 6G in Triton X-100 with and Without Silver NPs before and after exposure to UV irradiation.

\begin{tabular}{|c|c|c|c|c|c|c|}
\hline Dyes & $\begin{array}{c}\text { Before } \\
\text { adding silver }\end{array}$ & $\mathbf{E}_{\mathbf{g}}$ & $\mathbf{E}_{\mathbf{u}}$ & After adding silver & $\mathbf{E}_{\mathbf{g}}$ & $\mathbf{E}_{\mathbf{u}}$ \\
\hline \multirow{3}{*}{ Coumarin 6} & $\mathrm{~T}=0$ & 2.56 & 0.066 & $\mathrm{~T}=0$ & 2.47 & 0.073 \\
\hline & $\begin{array}{c}\mathrm{T}=960 \mathrm{~min} \\
\text { with filter }\end{array}$ & 2.51 & 0.069 & $\mathrm{~T}=960 \mathrm{~min}$ with filter & 2.47 & 0.075 \\
\hline & $\begin{array}{c}\mathrm{T}=960 \mathrm{~min} \\
\text { without filter }\end{array}$ & 2.49 & 0.071 & $\begin{array}{c}\mathrm{T}=960 \text { min without } \\
\text { filter }\end{array}$ & 2.43 & 0.077 \\
\hline \multirow{3}{*}{ Fluorescein } & $\mathrm{T}=0$ & 2.30 & 0.039 & $\mathrm{~T}=0$ & 2.27 & 0.051 \\
\hline & $\begin{array}{l}\mathrm{T}=960 \mathrm{~min} \\
\text { with filter }\end{array}$ & 2.29 & 0.041 & $\mathrm{~T}=960 \mathrm{~min}$ with filter & 2.27 & 0.052 \\
\hline & $\begin{array}{l}\mathrm{T}=960 \mathrm{~min} \\
\text { without filter }\end{array}$ & 2.28 & 0.042 & $\begin{array}{c}\mathrm{T}=960 \text { min without } \\
\text { filter }\end{array}$ & 2.26 & 0.054 \\
\hline \multirow{3}{*}{$\begin{array}{c}\text { Rhodamine } \\
\text { 6G }\end{array}$} & $\mathrm{T}=0$ & 2.19 & 0.044 & $\mathrm{~T}=0$ & 2.16 & 0.062 \\
\hline & $\begin{array}{l}\mathrm{T}=40 \mathrm{~min} \\
\text { with filter }\end{array}$ & 2.18 & 0.045 & $\mathrm{~T}=960 \mathrm{~min}$ with filter & 2.16 & 0064 \\
\hline & $\begin{array}{c}\mathrm{T}=35 \mathrm{~min} \\
\text { without filter }\end{array}$ & 2.17 & 0.046 & $\begin{array}{c}\mathrm{T}=960 \text { min without } \\
\text { filter }\end{array}$ & 2.15 & 0.067 \\
\hline
\end{tabular}

\subsection{Photostability}

The stability of fluorescent dyes is one of the main factors in LSC development. To examine the stability of Coumarin 6, Fluorescien and Rhodamine 6G in Triton X-100, the absorbance was measured before and after irradiation with 300 Watt Xenon arc lamp with absorbing UV filter and without filter for 960 minutes. Silver NPs added to the above samples and measurements are repeated. Fig. 7 shows that improving stability of organic dyes used after addition of Silver NPs. This highlights the importance of Silver NPs especially with Rhodamine $6 \mathrm{G}$ which photo bleaching after exposure for 35 min without Silver. 

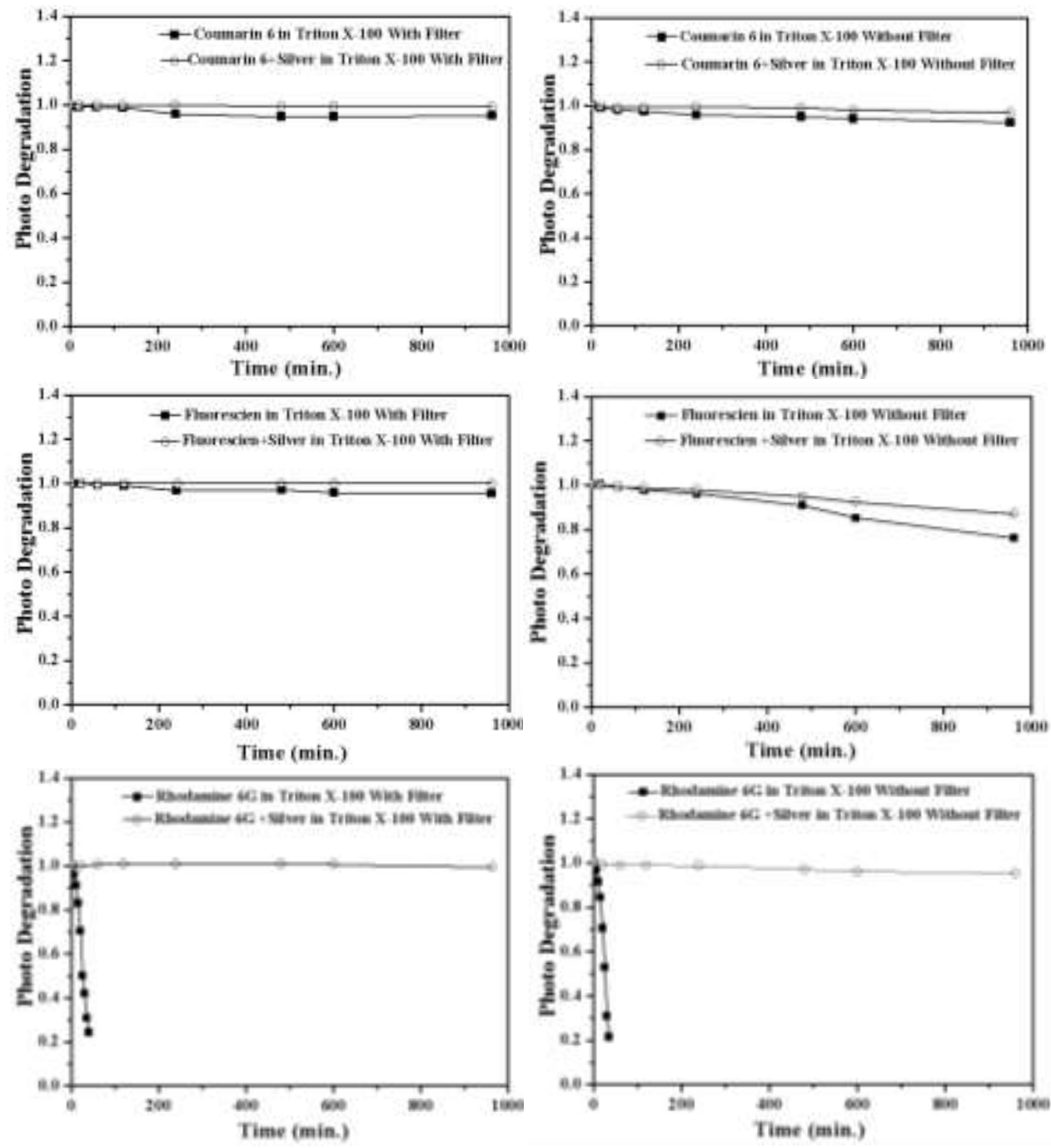

Fig. (7): The photo degradation of (a) Coumarin 6, (b) Rhodamine 6G and (c) fluorescien in Triton X-100 with and without filter before and after adding Silver NPs.

The stability of the organic dyes may be due to the interaction with surface Plasmon resonance (SPR) in metal particles; there is also interaction result in shorting of the excited-state lifetime thus improving the photo stability of the dye [10]. Rate constants of photo degradation of dyes estimated according to [20].

$$
K=\frac{2.3}{t} \log \frac{A_{o}}{A}
$$


where $A_{o}$ and $A$ are the absorption before and after UV irradiation, $t$ is the time of exposure in minutes, and $\mathrm{K}$ is the rate constant. The kinetics of photo degradation $(\mathrm{K})$ and half life time $\left(\mathrm{t}_{1 / 2}\right)$ of dyes/ Triton X-100 and dyes/Silver NPs/ Triton X-100, are listed in table (4). From Table 4, it is clear that $t_{1 / 2}$ values of three fluorescent dyes after adding Silver NPs are extremely increased; especially for Rhodamine 6G.

Table 4 The kinetics of photo-degradation $(K)$ and half life time $\left(t_{1 / 2}\right)$ of dyes/ Triton X-100 and dyes/silver NPs/ Triton X-100.

\begin{tabular}{|c|c|c|c|c|c|}
\hline \multirow{2}{*}{ Dyes } & Conditions & \multicolumn{2}{|c|}{ Without Filter } & \multicolumn{2}{c|}{ With Filter } \\
\cline { 3 - 6 } Coumarin 6 & $\begin{array}{c}\text { Before } \\
\text { adding silver }\end{array}$ & $8.37 \times 10^{-5}$ & 8278 & $5.33 \times 10^{-5}$ & 12984 \\
\cline { 2 - 6 } & $\begin{array}{c}\text { After adding } \\
\text { silver }\end{array}$ & $3.49 \times 10^{-5}$ & 19847 & $1.04 \times 10^{-6}$ & 665694 \\
\hline \multirow{2}{*}{ Fluorescein } & $\begin{array}{c}\text { Before } \\
\text { adding silver }\end{array}$ & $9.80 \times 10^{-5}$ & 7062 & $4.85 \times 10^{-6}$ & 14270 \\
\cline { 2 - 6 } & $\begin{array}{c}\text { After adding } \\
\text { silver }\end{array}$ & $5.22 \times 10^{-5}$ & 13255 & $1.24 \times 10^{-6}$ & 554690 \\
\hline \multirow{2}{*}{$\begin{array}{c}\text { Rhodamine } \\
\text { 6G }\end{array}$} & $\begin{array}{c}\text { Before } \\
\text { adding silver }\end{array}$ & $4.4 \times 10^{-2}$ & 15.74 & $\begin{array}{c}3.53 \times 10^{-} \\
3\end{array}$ & 19.59 \\
\cline { 2 - 6 } & $\begin{array}{c}\text { After adding } \\
\text { silver }\end{array}$ & $4.89 \times 10^{-5}$ & 14143 & $1.04 \times 10^{-6}$ & 653773 \\
\hline
\end{tabular}

\subsection{Enhancing the fluorescence of fluorescent dyes}

For LSC, it is important to have colorants with high transition probabilities of light absorption and emission. The addition of Silver (NPs) has been investigated as a means of enhancing the fluorescence of the selected fluorescent dyes. Silver NPs are used in most popular dyes because their Plasmon resonance frequency is located in the visible spectrum which matches with the absorption and the emission bands of these dyes. The florescence enhancement occurs due to the interaction between the electric dipole of the dye molecules and surface Plasmon of Silver (NPs) [21, 22]. Figure 8 shows the fluorescence spectra of Coumarin 6, Fluorescien and Rhodamine 6G in Triton $\mathrm{X}-100$ 

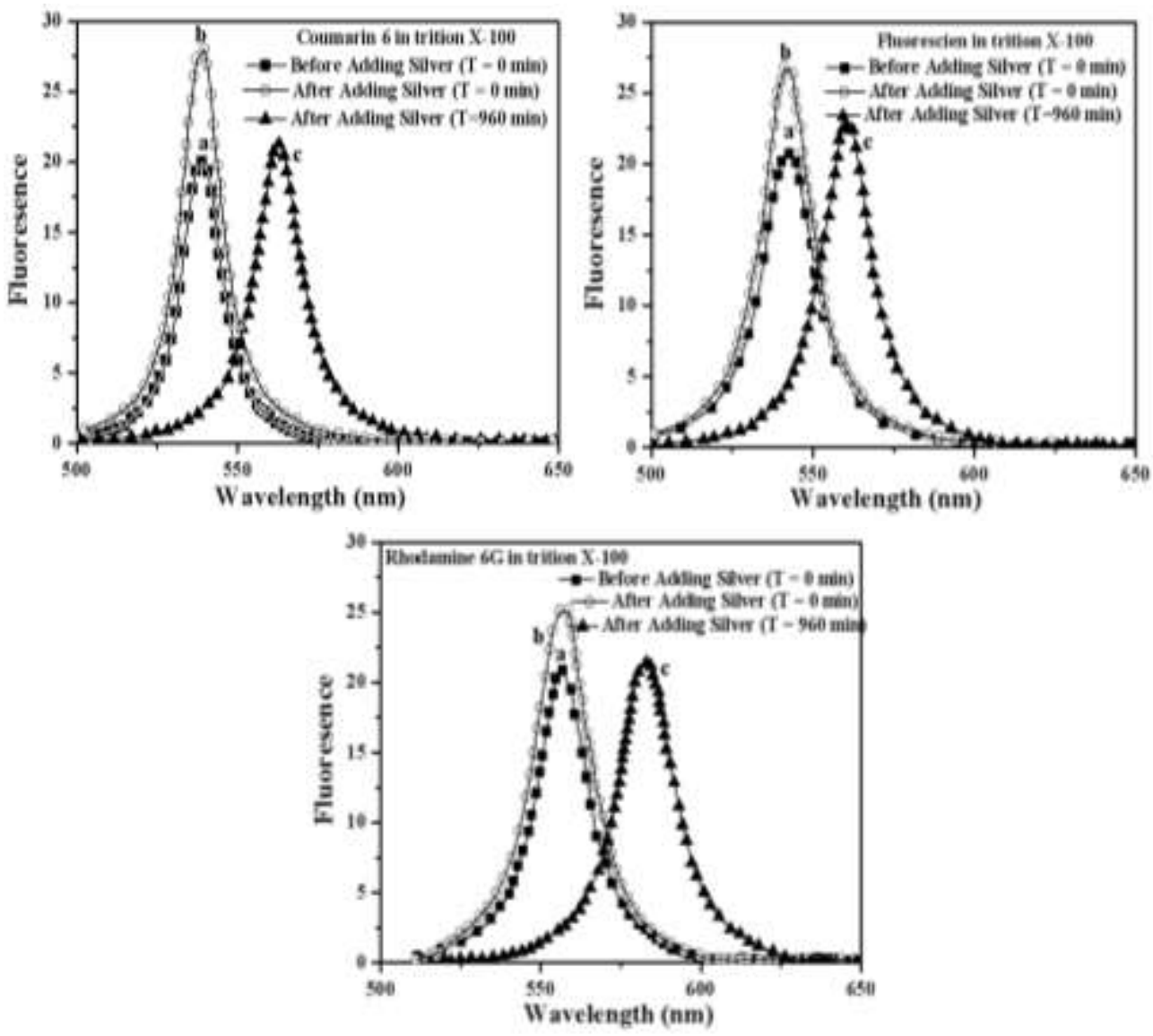

Fig. (8): Fluorescence spectra of Coumarin 6, Fluorescien and Rhodamine 6G in Triton X-100 (a) without Silver, (b) with Silver and (c) with Silver after UV irradiation.

without and with Silver NPs. From these figures, the addition of Silver NPs to dye solution causes the broadening of fluorescence curves. The area under fluorescence spectra calculated and listed in Table 5. It is clear from the table that the area increased by 41,31 and $36 \%$ for coumarin 6 , Fluorescein and Rhodamine 6G dyes, respectively in Triton X-100 with Silver NPs when compared with identical dye concentration without Silver NPs. Also, the fluorescence spectra of fluorescent dyes with Silver NPs after exposure to Xenon arc lamp 300 Watt without UV filter for 960 minutes decreased by $15 \%$. 
Table (5): The area under fluorescence curves for Coumarin 6, Fluorescien and Rhodamine 6G in Triton X-100 without, with Silver and with Silver after UV irradiation for 960 minutes.

\begin{tabular}{|c|c|c|c|c|c|}
\hline \multirow{2}{*}{ Dyes } & Conditions & $\begin{array}{c}\text { Absorbance } \\
\text { wavelength } \\
(\mathbf{n m})\end{array}$ & $\begin{array}{c}\text { Emission } \\
\text { wavelength } \\
(\mathbf{n m})\end{array}$ & $\begin{array}{c}\text { Stoke } \\
\text { shift }(\boldsymbol{\Delta} \boldsymbol{\lambda}) \\
(\mathbf{n m})\end{array}$ & $\begin{array}{c}\text { Area under } \\
\text { fluoresence } \\
\text { curve }\end{array}$ \\
\hline \multirow{4}{*}{ Coumarin 6 } & Without Silver & 440 & 538 & 98 & 486.60 \\
\cline { 2 - 6 } & $\begin{array}{c}\text { With Silver } \\
\text { before exposure }\end{array}$ & 440 & 540 & 100 & 686.65 \\
\cline { 2 - 6 } & $\begin{array}{c}\text { With Silver after } \\
\text { exposure }\end{array}$ & 455 & 562 & 107 & 585.68 \\
\hline \multirow{4}{*}{ Fluorescein } & Without Silver & 461 & 542 & 81 & 614.33 \\
\cline { 2 - 6 } & $\begin{array}{c}\text { With Silver } \\
\text { before exposure }\end{array}$ & 454 & 542 & 88 & 806.77 \\
\cline { 2 - 6 } Rhodamine & $\begin{array}{c}\text { With Silver after } \\
\text { (exposure }\end{array}$ & 472 & 562 & 90 & 684.93 \\
\cline { 2 - 6 } 6G & $\begin{array}{c}\text { Without Silver } \\
\text { before Silver }\end{array}$ & 525 & 557 & 32 & 639.58 \\
\cline { 2 - 6 } & $\begin{array}{c}\text { With Silver after } \\
\text { exposure }\end{array}$ & 526 & 583 & 57 & 738.54 \\
\hline
\end{tabular}

\section{Conclusion}

The challenges in LSC development have been highlighted and various means to overcome them have been discussed. One promising concept is the addition of Silver nanoparticles (NPs). Silver NPs in Triton X-100 was analyzed by different characterizing methods and it is confirmed the absorption band exhibited a red shift and broadening after UV Irradiation for 960 minutes. Also, the particle size calculated from absorption spectra. Changes in optical band gap values and Urbach's energy values after UV irradiation have been calculated. In this paper, we show how the fluorescence and photo stability of fluorescent dyes have been enhanced by their interaction with Silver NPs. 


\section{eferences}

1. W. Weber, J. Lambe, Appl. opt. 15, 2299 (1976).

2. Goetzberger, W. Greubel, Appl. Phys. 14, 123 (1977).

3. A. A. Erap, G. B. Smith, P. D. Swift, J. Franklin, J. Sol. Energy 76, 655 (2004).

4. S. T. Bailey et al., Sol. Energ. Mat. Sol Cell. 91, 67 (2007).

5. R. Reisfeld, Invited paper, Opt. Mater. 32, 850 (2010).

6. R. Reisfeld, TS. Saraidarov, V. Levchenko, Polym. Advan. Technol. (2010).

7. V. Levchenko, M. Grouchko, S. Magdassi, T. Saraidarov, R. Reisfeld, Opt. Mater. (2011), doi: 10.1016/ j. optmat, 04, 022 (2011).

8. Ts. Saraidarov, V. Levchenko, A. Grabowska, P. Borowicz, R. Reisfeld, Chem. Phys. Lett., 492, 60 (2010).

9. O. D. Bekasova, Inorg. Mater., 46, 1201 (2010).

10. O. G. Tovmachenko, C. Graf, D. J. Vanden Heuvel, Adv. Mater., 18, 91 (2006).

11. M. A. Noginov, G. Zhu, V. P. Drachev, Phy. Rev. B, 74, 184 (2006).

12. M. A. Noginov, G. Zhu, C. Davison, A. K. Pradhan, J. modern opt., 52, 2331 (2005).

13. A. I. Kryukov, A. L. Stroyuk, N. N. Zinchuk, A. V. Korzhak, S.Y. Kuchmii , J. of Mol. Catal. A: Chemical, 221, 209 (2004).

14. D. Manikandana, S. Mohan and K. G. M. Nair, Mat. Res. Bull., 38, 1545 (2003).

15. A. Pragatheeswaran, T. A. kareem and A. A. Kaliani., J. Phys.: Conference series, 208, 012109 (2010).

16. J. Tauc, R. Grigorovici and A. Vancu, Phys. Status Solidi (b), 15, 627 (1996).

17. R. Chahal, S. Mahendia, A. K. Tomar, Shymkumar, Digest J. of Nanomater. Biostruct., 6, 299 (2011).

18. T. Datta, J. A. Woollam, and W. Notohamiprodjo, Phy. Rev. B, 40, 5956 (1989).

19. S. M. Reda, Acta Materialia, 56, 259 (2008).

20. Grabchev and V. Bojinov, Polym. Degrad. Stabil., 70, 153 (2000).

21. B.C. Rowan, R.L. Wilson and B. S. Richards, IEEE J. Sel. Top. Quant., 14, 1312 (2008).

22. R. Reisfeld, TS. Saraidarov, V. Levchenko, J. Sol-Gel Sci. Technol., 50, 194 (2009). 